\title{
WORD FORMATION PROCESSES OF FASHION TERMS LISTED IN UK VOGUE'S WEBSITE
}

\author{
Aurelia Reza Hayuwardhani ${ }^{1}$ \\ ${ }^{1}$ Sanata Dharma University \\ Corresponding Author: Aurelia Reza Hayuwardhani e-mail: aureliareza@gmail.com
}

\begin{abstract}
ARTICLE INFO ABSTRACT

Received: 2019-08-15

Accepted: 2019-11-27

Published: October 2019

Volume: 3

Issue: 2

DOI:

https://doi.org/10.33019/lire.v

$3 \mathrm{i} 2.51$

KEYWORDS

Word formation, morphology, fashion terms, UK Vogue's

This paper aims to see the word formation processes in the fashion terms proposed by UK Vogue's website. There are twenty six terminologies listed from A to $\mathrm{Z}$. The terminologies became the data of the analysis in this paper. Each of the terminology was paid attention closely to identify the processes in the termilogies. The results show that fashion terms that are specifically listed on UK Vogue's website implement five kinds of processes: 1) eponym, 2) borrowing, 3) compunding, 4) affixation, and 5) multiple processes or combination of previously mentioned processes. Out of those processes, borrowing processes are commonly used in forming fashion terms. Thus, it can be inferred that the formation of fashion terms are linked to the language that contributes more words in the fashion terminology vocabulary.
\end{abstract} website.

\section{INTRODUCTION}

The development of fashion industry does not only affect economic sphere of ourlives, but it also gives effects to linguistic richness. This is due to the fact that the more phenomena in the society occur, the more words that are proposed to signify concepts we understand. In this case, fashion industry requires terminologies that are exclusivelly used in the world of fashion. As the evidence, in 2013 United Kingdom Vogue published a list of fashion terms that are commonly used. The list of fashion terms or referred as "The Vogue Glossary" on the official website suggest twenty six terminologies that are used in fashion world, specifically by Vogue as the biggest fashion media. The terminologies stated there are listed based on the alphabets.

Morphology, as defined by Booij (2007) is a part of linguistics that deal with one's understanding of a language covering the structures of words that carry meaningful aspects. In morphology, one of the topics in the range of morphological analysis is related to how words are formed. Word formation processes are varied. It can be as simple as putting $-s$ to mark a plural noun or even finding the root of a word that might be borrowed from other languages. By testifying the process of word forming, further, we can understand the language we learn or speak since we finally know how humans produce words and/ or phrases.

Relating the importance of understanding word formation processes with the fact that there is a fashion glossary published by UK Vogue representing the linguistic richness, this paper aims to explain the word formation processes implemented in the words listed in the glossary from A to Z. The initial hypothesis that the writer has is that the fashion terms listed on the online glossary 
are influenced by French words. To prove whether the hypothesis can be supported by objective explanation or not, the following chapters will explicate about it further.

\section{LITERATURE REVIEW}

\section{Eponym}

Eponym is a word formation process that becomes "mnemonic and commemorative device" (Merton, 1942). It means that this kind of process tries to acknowledge the one who established or contributed to the making or realization of certain concept or thing.

\section{Borrowing}

Borrowing is the process in which other words from other languages are borrowed to name certain concepts (Hatch \& Brown, 1995). The examples are sepur in Javanese that was borrowed from Dutch spoor meaning a train. Besides there is jongos in Indonesian referring to a male maid, jongens in Dutch that means young men.

\section{Compunding}

This process refers to a very broad process of joining two or more words in order to make new words (Fromkin et. al, 2003). In compunding, possible constructions can be noun + noun like cupboard and homework, and adj + noun like hotdog and greentea. Every compounded word has a head which defines the overall meaning (Fromkin et. al, 2003).

\section{Affixation}

A word forming process that allows a bound morpheme, either derivational or inflectional, to be combined with a stem or root (Szyzmanek, 1989). Examples of it are im + mature = immature, stupid + ity $=$ stupidity , and $i r+$ replace + able $=$ irreplacable .

\section{Multiple Processes}

Mutiple processes referred here means that the word forming processes in a word involve more than one process. It can be two or more than two processes attached. The explanation on multiple processes will cover word formation processes that are combined to realize certain word.

\section{METHODOLOGY}

The research in this paper was mainly based on descriptive-qualitative method. It is due to the fact that the explication of the results is in the form of description. There will be numbers showing the occurence of each word forming process. However, it does not give further significance than to merely show readers which one is the most populous process done in realizing those fashion terms. Therefore, we can say that this paper is based on descriptive-qualitative method. 


\section{RESULTS AND DISCUSSION}

\section{Eponym}

\section{Raglan}

The eponym is in the word raglan. In the website, this word is defined as "the style of a sleeve, where a continuous piece of fabric continues to the neck with no shoulder seam" (Conlonn, 2013). The shape of the style referred through the word raglan is similar to what Lord Raglan who was the commander of the British troops during the Crimean war wore. This is in line with the explanation on the word origin of raglan itself. According to Merriam-Webster's, this word was derived from his name since the style that raglan defined by Vogue is inspired by his suite during the Crimean war.

\section{Borrowing}

\section{Appliqué}

Conlonn (2013) in UK Vogue's website defines appliqué as “a decorative design made og one pice of fabric sewn on top of another". This word, as seen from the existence of the alphabet $e$ that makes this word sounds identically a French. It is true that now this fashion term exists in French. However, French borrows this word appliqué from a Latin word applicare (Appliqué, n.d.). Some adaptations, including the addition $e ́$ and deletion care from the original word, make this word become a French word now. Thus, we can say that this fashion term is borrowed from Latin because the status of the word in French is a borrowed word as well.

\section{Filigree}

The definition of filigree is "ornamental work of fine wire, usually in silver or gold, with the addition of tiny beads" (Conlonn, 2013). This refers to a method in jewelery making that has been used since $3000 \mathrm{BC}$. The characteristic of this jewelery is its girly finish. This word is derived from a French word filigrane or filigrana in Italian. However, this terminology was originally adopted from a combinaton of two Latin words which are filum meaning thread and granum meaning seed (Filigree, n.d.). The shape of filigree itself is identical with the seeds that are combined together into a thread. Thus, we can conclude that filigree is borrowed from Latin since Latin is the language base of the original words.

\section{Gaiter}

This word means "a piece of fabric worn over the shoe, extending to the ankle or the knee" (Conlon, 2013). This fashion stuff is actually a common clothing item in military. This is used to protect the troops' ankles, yet in fashion it gives aesthetic value to the one who wears it. The word 
gaiter has been borrowed from French word guêtre since the 18th century and was actually derived from Germanic language base (Gaiter, n.d.).

\section{Iridescent}

It means "the property of a fabric that appears to change colour as it catches the light" (Conlon, 2013). This word is considered as an adjective that usually can be given to a fashion item that can has such quality. The easiest example we can find in our surrounding is a sea shell. A sea shell can change colour when the light of the sun cathes the shell. The effect that eyes can spectate is called as iridescent. This word was borrowed from Latin iris or irid- meaning rainbow (Iridescent, n.d.).

\section{Ombré}

This means "a gradual change of one shade from dark to light (also referred to as degradé)" (Conlon, 2013). This word is borrowed from a French word that is in past participle ombrer meaning to shade. This kind of colour transition is popular in fashion industry. Many popular brands use this color transition into their collections. This, therefore, also popularizes this term to be used in daily life.

\section{Quarter}

Quarter in fashion world means "the section of a shoe that covers the heel" (Conlon, 2013). This word was borrowed from Latin word quartarius meaning fourth part of a measure. The idea of making this borrowed Latin word into the definition in terms of fashion industry is that the section of a shoe only covers certain part of a measure, in this case a shoe.

\section{Seersucker}

Seersucker is word to describe "a thin, puckered, cotton fabric" (Conlon, 2013). This kind of fabric is usually produced by the process of stitching in order to make air circluation for clothes that are going to be made from this fabric. This kind of fabric is a common fabric people wear in summer time. The word seersucker was borrowed from Persian words رىش رش shîr and shakar which mean milk and sugar (Seersucker, n.d.). They refer to the smoothness of milk and roughness of sugar.

\section{Trompe L'Oeil}

Tromple L'Oeil refers to "an artistic technique where realistic imagery is used so to appear three dimensional" (Conlon, 2013). This is typically used to refer to a painting, but it is not limited to fashion. The three dimensional portrayal is illusional only and intended to give aesthetic pleasure. The phrase trompe l'oeil is borrowed from a French word trompe-l'oil which literally means something that creates illusions or deceives our eyes (Trompe l'oeil, n.d.).

\section{Vent}


Vent is "a split in a garment to allow for movement" (Conlon, 2013). This split is usually put on the back part of a garment. We can usually find it on skirts to enable the users of the skirts move easier. This word is borrowed from Anglo-French word fente which means "split, crack, opening" (Vent, n.d.) and adapted into vent by replacing the $f$ with $v$ and the ending $t e$ into $t$.

\section{Yoke}

Yoke itself is "the part of the garment around the neckline o the front and the back" (Conlon, 2013). The original word that is borrowed to mention yoke is from Germanic language. In Middle English it was yok, Old English geoc; or Greek zygon. In the 12th century, the word yoke was defined as a thing that joined two animal heads or necks for making them work together. The sense of bounding the neck influences the derivation of the word yoke we understand now.

\section{Zori}

Zori is a "Japanese sandal" (Conlon, 2013). It can also be said as fliplops with a special sole that looks like a straw that are from Japan. Based on the definition, we can directly understand that this term is borrowed from Japanese without any adaptation. The original word is maintained in the fashion term.

\section{Compunding}

Herringbone

The word herringbone in fashion industy means a quality that shows "a V-shaped weave resembling the skeleton of a herring fish" (Conlonn, 2013). From the definition mentioned previously, we notice two important keywords in defining this fashion term. They are herring referring to a kind of fish, and skeleton or bone. The keywords here are in words that are combined together to make a compound word herringbone referring to a pattern of fabric that looks like the bone of herring fish.

\section{Knife Pleat}

From the phrase, we can tell that this is formed by combining two words which are knife and pleat. Knife pleat itself means "a sharp, narrow fold" (Conlonn, 2013). This refers to a shape that women often find on skirts that show folded fabric. The word pleat itself already refers to multiple folds in a fabric, but the word knife adds the quality of the thing referred as a sharp one.

\section{Lettuce Hem}

Lettuce Hem is "the result of fabric being stretched as it is sewn, resulting in a way hemline" (Conlon, 2013). It does not refer to a type of vegetables, yet it resembles the shape of the vegetable lettuce since the shape looks layered and irregular. The word hem refers to the outer part of a clothing, usually the edge. Therefore if both lettuce and hem are put together, they will mean 122

Copyright ( 92019 Aurelia Reza Hayuwardhani

\section{(a) (1) ()}


that it refers to the edge of a garment that shapes like lettuce in a way that it is layered and irregular.

\section{Mandarin Collar}

This is a type of collar that is "small, close fitting and upright" (Conlonn, 2013). This is called as Mandarin since the quality of the shape looks like Chinese style clothes. Mandarin Collar is considered as a compound word since there are two elements that are put together to make a new meaning. Previously, if we refer to the original meaning of collar, it will be very ordinary because it refers to any shirts that have collar. However, by adding Mandarin before the word collar, the thing becomes specific since it refers to a collar having Mandarin-like style.

\section{Paperbag Waist}

Here in paperbag waist we notice that there are two compounding processes. First process is seen from the word paperbag. We attach paper and bag which literally means a bag that is made from paper. The second process, the result of compounding process in the first is attached with a word which is waist. The meaning of paperbag waist, then after the compounding processes, is different from the meaning that is understood through word per word.

\section{Affixation}

Boxy

The terminology boxy in fashion world means "square in shape with minimal tailoring" (Conlonn, 2013). From the definition we can infer that there is a morphological process called as affixation in making this word. The definition that contains "square in shape" refers to the shape of a box which is definitely square. However, since box is a noun, the $-y$ attached to the word box is to state that the word boxy is adjective that is used to explain a certain quality.

\section{Neats}

Neats are "small socks with evenly-spaced designs" (Conlonn, 2013). Since neats are defined as small socks, in plural, we notice that there is an affix $-s$ to tell that the terminology neats shows a plural noun. If we delete the $-s$, the meaning becomes only a small sock. This will sound odd since socks typically come in pairs.

\section{Multiple Processes}

\section{Cap Sleeves}

The meaning of this phrase is "a sleeve that sits in between sleeveless and short" (Conlonn, 2013). This refers to a sleeve that is not really short, but it is not long as well. Here, the processes that can be seen from the word formation are two. First, it is compounding. The compounding happens when the word cap and sleeve are combined together to make a new meaning of the style referred. Second, the affixation is another process noticed here. The affixation happens when $-s$ 
plural marker is attached to the word sleeve meaning that the clothing item is in pairs, it does not only refer to one sleeve.

\section{Dirndl Skirt}

This refers to "a full, wide skirt with a tight, fitted waistline" (Conlonn, 2013). The word dirndl is borrowed from the German word dirndl to define a traditional dress worn by women in Austria. The word skirt is added to specify that the clothing item is a skirt. Thus, the combination of two processes: a borrowing by the word dirndl and compounding the borrowed word with an English word skirt represent multiple processes in formulating this terminology.

\section{Epaulettes}

The word epaulettes contain two word forming processes. First, this word is borrowed from French. Epaultette refers to the ornament that is put on the shoulder as a part of military uniform. Second, the process is called as affixation. The affixation happens when the plural marker $-s$ is attached to show that epaulette must be more than one since they are put on both shoulders. Therfore, the affixation is needded to strengthen the borrowed word itself.

\section{Jouy Print}

This phrase means "a white or off-white background on which a repeated pattern, depicting a detailed scene, appears" (Conlon, 2013). This pattern is characterized by a single pattern containing correlations within each picture in the pattern that is repeated over the whole fabric. Jouy print or "fabric of Jouy" is considered as a word containing multiple processes. Since there is an eponym since the word Jouy itself is derived from a name of a city in France named Jouy-en-Josas. Furthermore, the eponym is compounded with another word which is print. Therefore, we can conclude that this phrase contains multiple processes: eponym and compounding.

\section{Unitard}

It is "a skin-tight garment that covers the body from the neck to the wrists and ankles" (Conlon, 2013). Before it becomes the word unitard, there are morphemes that are joined together. They are uni- means singleand leotard, in which only the tard is taken. The word leotard is an eponym since this is to acknowlegde Jules Léotard, a trapeze artist, who performed with this type of clothing item. Therefore, this word contains multiple processes since there is an affixation with the attachment of uni- and an eponym from the other part of the word which is -tard.

\section{Welt Pockets}

They refer to "a pocket set into the garment with a slit entrance, as opposed to a patch or flap" (Conlon, 2013). The pocket here is almost invisible since it is tailored to make the appearance of the garment neater.The processes happening here are similar to the processes in part 
(i) which indicate that there are compounding, in terms of the combination of welt + pocket as well as affixation in terms of the attachment of the plural marker $-s$ into the word pocket.

\section{X-ray Fabrics}

They are fabrics that are sheer and transparent (Conlon, 2013). If we take a look at $X$-ray Fabrics, there are three morphological processes. First, $X$-ray is a borrowing from German word $X$-Strahlen. Second, there is a compounding process happening in the combination of $X$-ray and fabric. Third, or the last, the process is affixation seen through the attachment of the plural marker $-s$ showing that the fabric is more than one.

\section{CONCLUSION}

Fashion terms have been developing since then. They help to define concepts in fashion industry by means of linguistic products which are words. Words are formed in many ways. They can be formed based on the combination of existing words, by borrowing words from other languages, and even internal processes like affixations. Even, they can be combined together to create new words with surely with new meanings.

In this paper, fashion terms taken from UK Vogue's website were seen in order to see how they were formed. The results show that there are five word formation processes implemented to propose the concepts delivered through the fashion terms. Eponym is the first process which has the least member. It is only constituted by one term listed in the UK Vogue's fashion glossary. Then, borrowing is the second process. This process is the most populous process found in the data. 11 out of 26 words from the glossary contain borrowing processes. The borrowing processes were mainly done by absorbing Latin and French words. From this phenomena we can infer that those two languages have a very strong impact in the formulation of the fashion terms listed on the web.

Besides, multiple processes in word formation also prove us that it is possible to form new words by using several processes. They can be compounding, affixation, and borrowing. Surpisingly, the number of words showing multiple processes is quite high. It refers that multiple word forming processes are possible to go through many revisions until a concept is well delivered in an arrangmenet of words.

Thus, from the paper we can conclude that the word formation processes in fashion terminologies are varied, yet the most influential process one is the borrowing process. From the borrowing process, specifically, we can infer that fashion terms are influenced by cultures that mainly create authentic cultures such as French, and Latin. Further research on more complete terminologies are welcomed to strengthen the results from this paper. 
LIRE JOURNAL (JOURNAL OF LINGUISTICS AND LITERATURE)

P-ISSN: $2598-1803$

E-ISSN: 2581-2130

Volume 3 Number 2 October 2019

\section{ABOUT THE AUTHOR(S)}

The author is the graduate student of English Language Studies, Sanata Dharma University in Yogyakarta, Indonesia.

\section{REFERENCES}

Appliqué. (n.d.) In Merriam-Webster's collegiate dictionary. Retrieved from https://www.merriam-webster.com/dictionary/appliqu $\% \mathrm{C} 3 \% \mathrm{~A} 9$.

Booij, G. (2007). The Grammar of Words: An Introduction to Linguistic Morphology. New York: Oxford University Press.

Conlonn, S. (2013, Oct 17). The Vogue Glossary. Retrieved from https://www.vogue.co.uk/gallery/the-vogue-glossary.

Filigree (n.d.) In LEXICO by Oxoford, Retrieved June 22, 2019 from https://www.lexico.com/en/definition/filigree.

Fromkin, V. et.al. (2003). An Introduction to Language. Massachusetts: Wadsworth.

Gaiter (n.d.) In LEXICO by Oxoford, Retrieved June 22, 2019 from https://www.lexico.com/en/definition/gaiter.

Hatch, E. \& C. Brown (1995). Vocabulary Semantic and Language Education. Cambridge: Cambridge University Press.

Merton, R.K. (1942). Science and technology in a democratic order. Journal of Legal and Political Sociology, 1(1), 115-126. doi:2027/mdp.39015008014428.

Raglan [Def. 2]. (n.d.). In Merriam Webster Online, Retrieved June 20, 2019 from https://www.merriam-webster.com/dictionary/raglan.

Seersucker (n.d.). The American Heritage dictionary of the English Language. Retrieved June 21, 2019 from https://ahdictionary.com/word/search.html?q=seersucker.

Szymanek, B. (1989). Introduction to Morphological Analysis. Warsawa: Panstwowe Wydawnictwo Naukowe.

Trompe 1'oeil. (n.d.) In Merriam-Webster's collegiate dictionary. Retrieved from https://www.merriam-webster.com/dictionary/trompe\%20l'oeil 